\title{
Effect of gonadotropins and alpha 2u-globulin on testicular steroidogenesis and spermatogenesis in melatonin-treated rats
}

\author{
R. Biswas ${ }^{1}$, N. M. Biswas², H. Mandal*, N. M. Biswas ${ }^{3}$ \\ ${ }^{1}$ Post doctorate fellow, Department of Oncology, National Cancer Institute, Bethesda, Maryland, USA \\ ${ }^{2}$ Associate Professor, Department of Medicine, NRS Medical College, Calcutta-14, India; ${ }^{3}$ Professor in Physiology, College of \\ Medical Sciences, Bharatpur, Nepal; *Deceased before this communication.
}

\begin{abstract}
Administration of melatonin ( $400 \mu \mathrm{g} / 100 \mathrm{~g}$ bd.wt.) for 14 days caused a fall in weights of the testes and accessory sex organs and testicular 17 $\beta$-hydroxysteroid dehydrogenase (17 $\beta$-HSD) but rise in $3 \beta$-hydroxysteroid

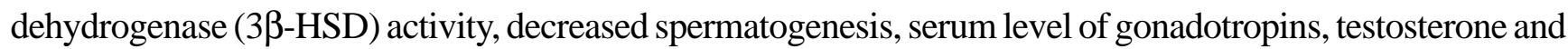
alpha $2 \mathrm{u}$-globulin, The animals treated with melatonin when received gonadotropins or alpha $2 \mathrm{u}$-globulin for the last seven days reversed the weight of testis and accessory sex organs, $3 \beta$-HSD, $17 \beta$-HSD activities, serum level of gonadotropins, testosterone and alpha $2 \mathrm{u}$-globulin when compared with melatonin-treated rats. It is concluded that alpha $2 \mathrm{u}$-globulin prevents testicular degeneration in melatonin-treated rats by stimulating the synthesis of gonadotropins.
\end{abstract}

Key words: Alpha 2u-globulin, gonadotropins, male gonad, melatonin.

\section{Introduction}

A sex-dependent urinary protein, alpha $2 \mathrm{u}$-globulin is synthesized in the liver and due to its small molecular size it is cleared by the kidneys in the adult male rats. ${ }^{1,2}$ Sexually mature male rats show diurnal rhythm of alpha 2u-globulin synthesis. ${ }^{3}$ Similar diurnal rhythm also occurs in melatonin synthesis from the pineal gland in rats. ${ }^{4}$ On the other hand melatonin treatment causes a substantial decrease in FSH together with testicular atrophy. ${ }^{5}$ While perfusion of the third cerebroventricle with melatonin lowers the plasma concentration of both FSH and LH in the adult rats. ${ }^{6}$ Melatonin treatment also decreases serum level of gonadotropins and alpha 2u-globulin along with the inhibition of testicular activity in the adult rats. ${ }^{7}$

Correspondence: N. M. Biswas

E-mail:drnmbiswas@gmail.com
The purpose of the present investigation was to determine whether external administration of FSH, LH or alpha $2 \mathrm{u}$-globulin can prevent testicular degeneration in melatonin-treated rats.

\section{Materials and methods}

Animal-Adult male rats of Sprague Dawley (Rattus norvegcus) strain weighing 150-200g were used in this experiment. A standard laboratory chow and water were available ad-libitum.

\section{Preparation of alpha 2u-globulin}

Alpha $2 \mathrm{u}$ globulin was isolated from male rat urine according to the method of Roy, Neuhaus and 
Harmison. ${ }^{8}$ The antiserum of alpha $2 \mathrm{u}$-globulin was raised in Dutch belted rabbits by injecting an emulsion of equal volume of alpha $2 \mathrm{u}$-globulin and freund's complete adjuvant. Immunoassay of serum alpha $2 \mathrm{u}$ globulin was carried out in calibrated plastic immunodiffusion plates as described previously ${ }^{9}$

\section{Melatonin, alpha 2u-globulin, FSH and LH treatment}

Forty rats were divided into five equal groups. Thirty two rats received subcutaneous injection of melatonin daily between 19.00 and $20.00 \mathrm{hr}$ for 14 days.

Melatonin received from Sigma Chemical Company, St. Louis, MD.USA, dissolved in vehicle (ethanol and water, 10:90, V/V) and injected $400 \mu \mathrm{g} / 100 \mathrm{mg}$ bd.wt./day. The melatonin treated rats were divided into four groups, one of which received no further treatment (Group II). From day eight of melatonin treatment, Group III animals treated with FSH and Group IV animals with LH. Both the hormones dissolved in distilled water and injected s.c. $25 \mu \mathrm{g} / 100 \mathrm{~g}$.bd.wt./day every morning for the last seven days. The animals of Group IV received alpha $2 \mathrm{u}$-globulin, dissolved in distilled water and injected s.c. at a dose of $1.5 \mathrm{mg} / \mathrm{rats} /$ day for the last seven days of melatonin treatment. Remaining eight animals received vehicle only (Group I). Blood was obtained from all the animals after $24 \mathrm{hrs}$ of last injection and serum was collected by centrifugation. All the animals were killed, the testes and secondary sex organs weighed.

\section{Assay of testicular $3 \beta$-HSD and $17 \beta$-HSD activities and testicular histology}

One testis of each animal was used to measure the activity of $3 \beta$-HSD and $17 \beta-H S D .{ }^{10,11}$ The remaining testis from each animal was fixed in Bouin's fixative and embedded in paraffin wax. Sections ( $5 \mu \mathrm{m}$ thick) stained with periodic acid-schiff-haematoxylin. Quantitative analysis of the seminiferous epithelium was carried out by counting the number of germ cell nuclei per cross section of the seminiferous tubule at the stage VII of the cycle of seminiferous epithelium. Germ cell nuclei were counted in 25 round tubular cross-sections at the VII of the cycle. All the nuclear counts of the germ cells were corrected for differences in nuclear diameter ${ }^{12}$ and for the tubular shrinkage by a sertoli cell correction fector. ${ }^{13}$

Hormone Assay - Serum FSH and LH were measured by radioimmunoassay according to the method of Moudgal and Madhwa Raj ${ }^{14}$ using reagents supplied by Rat Pituitary Distribution Program, NIAMDD, Maryland, USA. Serum samples were assayed in duplicate and gonadotropins were expressed as $\mu \mathrm{g} / \mathrm{litre}$ serum. The radioimmunoassay of testosterone was carried out as described by Auletta et al. ${ }^{15}$ The antiserum to testosterone was purchased from the Endocrine Science, USA, and had a $44 \%$ cross reactivity with dehydrotestosterone. The testosterone values are sum of testosterone and dehydrotestosterone, since chromatographic purification of the samples was not performed.

Data were analyzed by using Student's t-test.

\section{Results}

Adult rats were given melatonin for 14 days and killed on day 15 showed decreased testicular and accessory sex organ weights in comparison with vehicle - treated controls (Table-1). A reduced 17 $\beta$-HSD activity of the testis and serum alpha $2 \mathrm{u}$-globulin but an elevation of $3 \beta$-HSD activity of the testis was observed in melatonin treated rats. Serum levels of FSH, LH and testosterone 
R. Biswas, Effect of gonadotropins and alpha $2 u$-globulin on testicular.......

were reduced after melatonin treatment when compared with control animals. Histological examination of the seminiferous tubules at stage VII of the cycle revealed that melatonin treatment caused a marked reduction of type aspermatogonia, preleptotene spermatocytes and spermatids at this stage. The reduced weights of testes and sex-accessories caused by melatonin treatment were increased after $\mathrm{FSH}, \mathrm{LH}$ or alpha $2 \mathrm{u}$ globulin administration. The changes of the activities of steroidogenic enzymes and serum level of alpha $2 u-$ globulin due to melatonin treatment have been showed to improve towards the control values after administration of FSH, $\mathrm{LH}$ and alpha $2 \mathrm{u}$-globulin (Table-2). Serum levels of FSH, LH and testosterone were also increased after administration of $\mathrm{FSH}, \mathrm{LH}$ or alpha $2 \mathrm{u}$-globulin in relation in treated rats when compared with the rats treated with melatonin alone (Table-3). Testicular spermatogenic arrest due to melatonin treatment was reversed after administration of FSH, LH or alpha 2u-globulin (Table 4 \& 5).

Table 1: Weights of testis and accessory sex organs after administration of gonadotrophins and alpha $2 \mathrm{u}-$ globulin in Melatonin treated rats.

\begin{tabular}{lccc}
\hline Treatment & $\begin{array}{c}\text { Testis Weight } \\
(\mathbf{m g} / \mathbf{1 0 0 g} \text { bd.wt. })\end{array}$ & $\begin{array}{c}\text { Seminal Vesicle weight } \\
(\mathbf{m g} / \mathbf{1 0 0 g} \text { bd.wt. })\end{array}$ & $\begin{array}{c}\text { Ventral Prostate } \\
\text { (mg/100g bd.wt. })\end{array}$ \\
\hline Group I: Control animals & $1629.34 \pm 63.48$ & $435.45 \pm 37.25$ & $187.25 \pm 27.31$ \\
Group II Melatonin & $1271.67 \pm 46.32$ & $245.73 \pm 41.12$ & $73.46 \pm 26.57$ \\
Group III Melatonin + FSH & $1567.27 \pm 51.14$ & $401.19 \pm 42.25$ & $168.29 \pm 24.02$ \\
Group IV Melatonin + LH & $1551.38 \pm 42.42$ & $398.16 \pm 40.25$ & $171.18 \pm 24.25$ \\
Group V Melatonin + alpha 2u-globulin1552.18 \pm 47.12 & $412.39 \pm 32.38$ & $176.47 \pm 22.19$ \\
\hline
\end{tabular}

Values of Groups I, III, IV \& V are significantly different from the Group II $(\mathrm{P}<0.05)$.

*Each value represents mean \pm SE of 8 animals in each group.

Table -2: Testicular 3 $\beta$-HSD and 17 $\beta$-HSD activities and serum level of alpha $2 \mathrm{u}$-globulin after administration of gonadotropins and alpha $2 \mathrm{u}$-globulin in melatonin treated rats.

\begin{tabular}{lccc}
\hline Treatment & $\begin{array}{c}\text { 3ß-HSD activity } \\
\text { unit/mg of tissue/hr }\end{array}$ & $\begin{array}{c}\text { 17ß-HSD activity } \\
\text { unit/mg of tissue/hr }\end{array}$ & $\begin{array}{c}\text { Alpha 2u-globulin } \\
\text { mg/100 ml }\end{array}$ \\
\hline Group I: Control animals & $23.42 \pm 0.48$ & $25.87 \pm 0.58$ & $2.48 \pm 0.18$ \\
Group II Melatonin & $26.87 \pm 0.53$ & $21.98 \pm 0.55$ & $1.02 \pm 0.17$ \\
Group III Melatonin + F FSH & $23.21 \pm 0.48$ & $24.92 \pm 0.49$ & $2.22 \pm 0.21$ \\
Group IV Melatonin + LH & $23.14 \pm 0.51$ & $24.79 \pm 0.52$ & $2.18 \pm 0.16$ \\
Group V Melatonin + alpha 2u-globulin & $23.38 \pm 0.61$ & $24.68 \pm 0.62$ & $2.64 \pm 0.21$ \\
\hline
\end{tabular}

Each value represents mean \pm SE of 8 animals in each group. Values of the Groups I, III, IV \& V are significantly different from the Group II $(\mathrm{P}<0.05)$. 
Journal of College of Medical Sciences-Nepal, 2012, Vol-8, No-1

Table -3: Serum levels of FSH, LH and testosterone after administration of FSH, LH and alpha 2u-globulin in melatonin treated rats.

\begin{tabular}{lccc}
\hline Treatment & FSH $(\mu \mathrm{g} / \mathrm{L})$ & LH $(\mu \mathrm{g} / \mathrm{L})$ & Testosterone $(\mu \mathrm{g} / \mathrm{L})$ \\
\hline Group I: Control animals & $181.82 \pm 3.16$ & $38.18 \pm 1.41$ & $3.22 \pm 0.04$ \\
Group II: Melatonin & $143.37 \pm 2.05$ & $18.99 \pm 1.85$ & $2.17 \pm 0.03$ \\
Group III: Melatonin + FSH & $179.88 \pm 2.73$ & $36.41 \pm 2.05$ & $3.05 \pm 0.05$ \\
Group IV: Melatonin + LH & $163.18 \pm 3.07$ & $37.92 \pm 1.68$ & $2.98 \pm 0.04$ \\
Group V: Melatonin + alpha 2u-globulin & $174.28 \pm 2.98$ & $35.83 \pm 1.67$ & $3.09 \pm 0.06$ \\
\hline
\end{tabular}

Each value represents mean \pm SE of 8 animals in each group. Values of the Groups I, III, IV \& V are significantly different from the Group II $(\mathrm{P}<0.05)$.

Table -4: Quantitative analysis of spermatogenesis at stage VII in the seminiferous tubules after administration of gonadotropins and alpha $2 \mathrm{u}$-globulin in melatonin-treated rats.

\begin{tabular}{|c|c|c|c|c|}
\hline Treatment & $\begin{array}{c}\text { Preleptotene } \\
\text { Spermatocytes }\end{array}$ & $\begin{array}{c}\text { Type A } \\
\text { Spermatogonia } \\
\end{array}$ & $\begin{array}{c}\text { Pachytene } \\
\text { Spermatocytes } \\
\end{array}$ & Spermatid \\
\hline Group I: Control animals & $15.83 \pm 0.27$ & $0.56 \pm 0.04$ & $16.16 \pm 0.21^{*}$ & $56.86 \pm 1.22$ \\
\hline Group II: Melatonin & $13.61 \pm 0.33$ & $0.39 \pm 0.02$ & $15.92 \pm 0.26^{*}$ & $41.69 \pm 0.68$ \\
\hline Group III: Melatonin + FSH & $15.64 \pm 0.27$ & $0.51 \pm 0.04$ & $15.98 \pm 0.24 *$ & $49.72 \pm 1.16$ \\
\hline Group IV: Melatonin LH & $15.62 \pm 0.28$ & $0.49 \pm 0.03$ & $16.01 \pm 0.25^{*}$ & $50.19 \pm 0.98$ \\
\hline Group V: Melatonin alpha $2 \mathrm{u}$ & $\operatorname{lin} 15.78 \pm 0.26$ & $0.53 \pm 0.04$ & $16.07 \pm 0.18 *$ & $52.61 \pm 1.06$ \\
\hline $\begin{array}{l}\text { *Represent statistically nons } \\
\text { Group II }(\mathrm{P}<0.05) \text {. Each valu }\end{array}$ & $\begin{array}{l}\text { cant. Other Values } \\
\text { esents mean } \pm S E\end{array}$ & $\begin{array}{l}\text { Group I, III, IV, V } \\
8 \text { animals in each }\end{array}$ & $\begin{array}{l}\text { are significantly } \\
\text { roup. }\end{array}$ & nt from the \\
\hline $\begin{array}{l}\text { Table -5: Pachytene spermat } \\
\text { degeneration of step } 7 \text { spermat } \\
\text { rats. }\end{array}$ & $\begin{array}{l}\text { Spermatid ratio } \\
\text { administration } 0\end{array}$ & $\begin{array}{l}\text { e seminiferous } \mathrm{t} \\
\text { ladotropins and a }\end{array}$ & $\begin{array}{l}\text { le at stage VII } \\
\text { a } 2 \text { u-globulin ir }\end{array}$ & $\begin{array}{l}\text { oncentage of } \\
\text { onin-treated }\end{array}$ \\
\hline$\overline{\text { Treatment }}$ & Pachy & ne Spermatocyte: & $\%$ of & rmatid \\
\hline & & rmatid ratio & $\operatorname{dege}$ & ration \\
\hline Group I: Control animals & & $1: 3.52$ & & \\
\hline Group II: Melatonin & & $1: 2.62$ & & \\
\hline Group III: Melatonin + FSH & & $1: 3.11$ & & \\
\hline Group IV: Melatonin + LH & & $1: 3.13$ & & \\
\hline Group V: Melatonin + alpha 2 & pulin & $1: 3.27$ & & 25 \\
\hline
\end{tabular}




\section{Discussion}

These results show that administration of gonadotropins or alpha $2 \mathrm{u}$-globulin in melatonin-treated rats increased serum level of testosterone and prevented the arrest of spermatogenesis. Melatonin treatment of rats stimulated testicular 3 $\beta$-HSD and inhibited 17 $\beta$-HSD in a manner comparable to estrogen treated rats. ${ }^{16}$ The reduction of $17 \beta$-HSD activity after melatonin treatment is possibly due to reduced gonadotropin secretion. On the other land $17 \beta-H S D$ is one of the key enzymes of androgen synthesis. So the decreased level of gonadotropin dependent serum testosterone after melatonin treatment is, therefore, a reflection of reduced secretion of pituitary gonadotropins. The stimulation of $3 \beta$-HSD activity may increase the synthesis of progesterone as suggested in studies using slices of testis taken from estrogen -treated rats. ${ }^{17}$ The quantitative analysis of seminiferous tubules at stage VII of the cycle revealed that melatonin treatment reduced the number of spermatogonia, preleptotene spermatocytes and spermatids. Theoretically the pachytene spermatocytes: Spermatids ratio should be $1: 4^{13}$ in our control ratio is $1: 3.52$ i.e. $12 \%$ of spermatid degeneration. This ratio became 1:2.62 in the melatonintreated rats indicating that during the process of conversion of spermatocyte to spermatid $34.50 \%$ of the cells degenerated. Since FSH inhibits degeneration of spermatogonia ${ }^{18}$ and conversion of pachytene spermatocyte to spermatid which requires LH-induced testosterone ${ }^{19}$ in the present experiment spermatogenic arrest and degeneration of spermatocytes have been prevented in melatonin treated rats after administration of FSH, LH or alpha 2u-globulin. So the stimulation of spermatogenesis and testicular steroidogenesis in melatonin-treated rats is possibly an indirect effect of alpha 2 u-globulin by inducing pituitary gonadotropins. ${ }^{16}$

\section{References}

1. A.K. Roy, O.W. Neuhaus. Identification of rat urinary protein by Zone and immunoelectrophoresis. Proceeding of the society for the experimental biology and medicine 1966a; 121:894-9.

2. A.K. Roy, O.W. Neuhaus, Proof of the hepatic synthesis of a sex- dependent protein in the rat. Biochemica et Biophysica Acta. 1966b; 127:82-7.

3. H.K. Driscoll, M.C. Crim, J. Zahringer et al. Hepatic synthesis and urinary excretion of alpha $2 \mathrm{u}$-globulin by male rats: diurnal rhythm and response to fasting and refeeding. J. Nutr 1978; 108 (10): 1691-1701.

4. D.C. Kleim, J.L. Weller. Indole metabolism in the pineal gland: circadian rhythm in $\mathrm{N}$-acetyl transferase. Science 1970;169 (950): 1093-5.

5. L. Debeljuk, V.M. Feder, O.A. Pouluecci, Effect of treatment with melatonin on pituitary testicular axis of male rats. $J$. Repro.\& Fertility 1970; 21:363-4.

6. I.A. Kamberi, R.S. Mical, J.C. Porter. Effects of melatonin and serotonin on the release of FSH and prolactin. Endocrindogy 1971;88:1288-93.

7. H. Mandal, P.K. Ghosh, N.M. Biswas. Effect of dihydrotestosterone on serum concentrations of alpha2u-glolbulin and on spermatogenesis in metalonin treated rats. J. Endocrinology 1990;126:431-5.

13. Y. Clermont, H. Morgentaler. Quantitative study of spermatogenesis in the hypophysectomized rat. Endocrinology 1955; 57:369-82.

14. N.R. Moudgal, H.G. Madhwa Raj, Pituitary gonadotropins. In method of Hormone Radio immunoassay 1974; 57-85, Eds B.M. Jaffe \& N.R. Behrman, New york: Academic Press. 
Journal of College of Medical Sciences-Nepal, 2012, Vol-8, No-1

15. F.J. Auletta, R.V. Caldwell, G. Hamitton. Androgens : testosterone and dehydrotestosterone, in methods of hormone Radioimmuno assy 1974; 359-70, Eds B.M. Jaffe \& H.R. Behrman, New york: Academic Press.

16. N.M. Biswas, P.K. Ghosh, K.K. Ghosh et al. Effect of alpha $2 u$-globulin on serum concentration of gonadotropins and testicular activity in estrogen-treated rats. Endocrinology 1983;96:321-27.
17. N.R. Kalla, B.C. Nisula. R. Menard et al. the effect of estradiol in testicular testosterone biosynthesis. Endocrinology 1980;06:35-9.

18. A.R. Means, Biochemical effect of FSH. on the testis. In Handbook of Physiology 1975;5: Sect.7, PP-203-17, Eds. D.W. Hamilton \& R.O. Greep. Washington DC, American Physiological Society.

19. E. Steinberger, Hormonal control of mammalian spermatogenesis. Physiological Rev. 1971;51:1-22. 